\title{
Salt and Water
}

\section{Salt transport}

\author{
D. S. PARSONS \\ From the Department of Biochemistry, University of Oxford, South Parks Road, Oxford
}

It appears that the movement of salt across epithelial tissues is the result of the functioning of cellular systems, the physiological architecture of which depends upon membrane function. It also seems that the principles underlying the processes of salt absorption by the mammalian, including the human, small intestine are similar to those found to occur in other epithelial tissues. In the present account, attention will therefore be directed to some of the principles underlying active and passive transport across membranes and across cells, and to the fact that the processes in the intestine which are concerned with sodium and chloride transport seem to be fundamental to many, perhaps all, of the absorptive functions of the small intestine. I also propose to discuss the absorption of chloride ions by the small intestine and to draw attention to the changes in acid-base metabolism which seem to be associated with the intestinal absorption of salt. Finally, I shall describe some experiments which point to a fundamental role of $\mathrm{CO}_{2}$ in salt absorption by the jejunum. Most of this account will deal with the phenomena of salt absorption from the small intestine.

\section{Membrane Transport}

About 150 years ago the 'cell theory' became established (eg, Schwann, 1847). According to this theory the physiological functions of tissues could be explained in terms of the functioning of the individual cells of which the tissue was composed. According to the membrane theory, which we may regard as the modern counterpart, the physiological activities of individual cells stem from the operations of specific biochemical systems for transport residing in the limiting membranes of the cell. It is certainly true that the ionic exchanges which form the basis of the conduction and excitation in nerve and muscle and of junctional transmission depend upon membrane transport phenomena (eg, Hodgkin, 1964; Katz, 1966). Membrane transport phenomena underlie the translocation of ions and of other substances, including sugars and amino acids, across epithelial layers such as the intestine.

Upon the functioning of endergonic transport or processes localized in the limiting membranes of the $\vec{c}$ cell depends the capacity of all animal cells to maintain a stable volume. Transport through membranes therefore represents a fundamental physiological activity of living animal cells. The phenomena of transcellular transport, that is to say, absorption into, and secretion from, an epithelial sheet, appear to depend upon the differential dis- $\vec{\varphi}$ position of a specific membrane transport process $v$ located within the membranes at the two opposio ends of the individual absorbing cells (Figs. 1 and 4 . It is possible to regard the role of membrane fune tion in transcellular transport as a specialized devèlopment which has evolved from the fundamental ability of cells to regulate their volume (eg, Parsons, $\stackrel{\mathbb{Q}}{\mathscr{D}}$ 1967; Dowben, 1969).

\section{ACTIVE AND PASSIVE TRANSPORT}

The intestinal mucosal epithelium may be regarded as a compartment, the input and output to and from which may be observed and measured. A net movement of substance through the individual cells which comprise the epithelium (translocation) may occur up or down gradients of concentration or $\frac{\rho}{3}$ electro-chemical potential existing across the epithelium. If the movement occurs uphill, then by $\frac{}{2}$ definition the movement is 'active' and can be $?$ referred to as transcellular 'active' transport. In such instances, somewhere within the system work $N$ must be done upon the molecules or ions which are subjected to transport. The occurrence of trans- $N$ cellular active transport does not, of course, provide $\mathrm{\omega}$ evidence as to the stage or stages within the system at which the energy is utilized. Conversely, the fact $\bullet$ that transcellular translocation occurs across an $\mathbb{\Phi}$ epithelial layer down an electrochemical gradient? ('passive transport') does not exclude the presence of energy-dependent steps at certain stages within the system. 

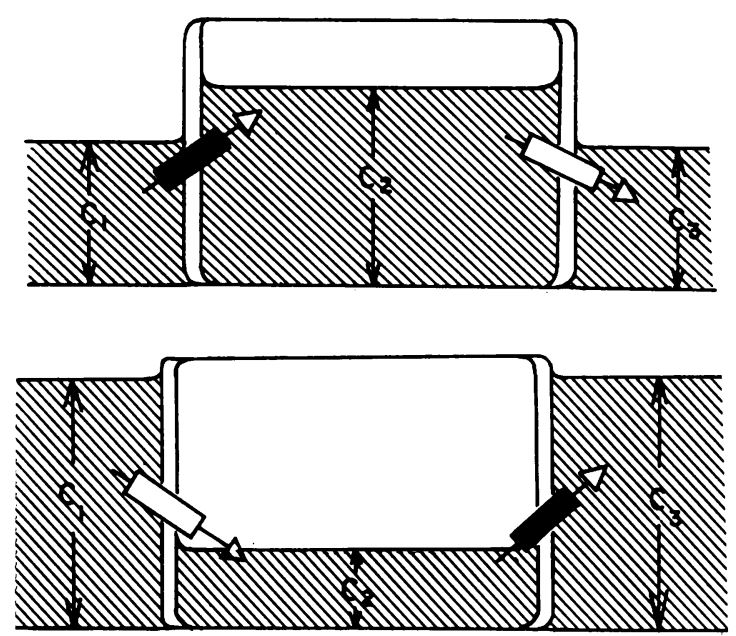

\section{Transmembrane transport}

As in the case of transcellular transport, the term 'active transport', when used with respect to membrane transport, must be considered to be meaningful only from the operational point of view. 'Active transport' is said to occur across any system, membrane, or cell when there is a flux of substance across that system occurring at a rate and in a direction which cannot be accounted for by the magnitude and sign of electrochemical potentials of that substance which exist externally to the system on either side. Therefore when an uncharged substance is transported across a biological membrane against a concentration gradient, active transport is said to occur. Clearly, in this case the work that has to be done in moving the transported substance through the membrane must be derived from energy-yielding processes occurring within the cell. The molecular structures underlying the chemical mechanisms which exist in the relevant membranes and the coupling between the energy-yielding process and the substrate flux must form part of the architecture of the membrane.

\section{Transepithelial transport}

Transcellular transepithelial transport appears to depend upon the operation of either one of two sorts of cellular system. In one sort (Fig. 1) the material transported (the 'substrate') is accumulated within (ie, pumped into) the cell and leaks out at the cell base, ${ }^{1}$ passively 'downhill' in the direction of the blood vessels. It is this sort of system which is

From the operational point of view, the 'base' of the mucosal cell comprises all the membranes which form the boundaries of the cell below the terminal bar. Morphologically, a substantial fraction of these membranes comprises the lateral membranes which form the boundaries of the intercellular spaces of the epithelial sheet.
Fig. 1 Model cell for transcellular transport. Cell membranes furnished with input system, 'pump', to move substrate 'actively' into the cell against concentration gradient $\left(c_{2}-c_{1}\right)$. Accumulated substrate moves 'passively' out of the cell through leaks down concentration gradient $c_{2}-c_{3} \cdot c_{1}=$ Concentration in lumen; $c_{2}=$ concentration within cell; $c_{3}=$ concentration in tissue fluid.

Fig. 2 Model cell for transcellular transport. Cell membranes furnished with output system, 'pump', to move substrate 'actively' out of cell against electrochemical gradient $c_{3}-c_{2}$. Substrate, eg, Na-ions, moves 'passively' into cell down electrochemical gradient $c_{1}-c_{2}$.

believed to be responsible for the transport of the hexoses and of the amino acids. In the other sort (Fig. 2), the sodium transporting cell, for example, ions are pumped out of the cell in the direction of the blood vessels. In this case the entry into the cell from the intestinal lumen is 'downhill' and therefore passive.

\section{Salt Transport}

This process is fundamental to intestinal absorption. The transport of $\mathrm{NaCl}$ accounts for most of the net ionic traffic observed to occur across many epithelia. Thus across frog skin and toad bladder the transcellular ionic traffic consists almost entirely of sodium accompanied by chloride. More moles of sodium than of any other ion are reabsorbed by the renal tubules of mammals and either sodium or chloride is the predominant ion present in the fluids of the gastrointestinal secretions. This $\mathrm{NaCl}$ which enters the gastrointestinal tract is, for practical purposes, all reabsorbed. The presence of $\mathrm{NaCl}$ in solution is an important feature of the intestinal luminal environment of the mucosal epithelial cells.

In man, the gastrointestinal secretions present to the intestine a daily load of water and salt which considerably exceeds the dietary intake. Thus, as shown in Table I, the total load of salt presented for net absorption by the adult human intestine amounts to some $750 \mathrm{mM}$ in 8.5 litres of water, and of this only one-fifth is derived from the diet.

It is now believed that the membrane transport of salt is closely coupled to the transport of other substances such as amino acids and sugars (Schultz and Curran, 1970). Indeed, it is the movement of sodium ions 'downhill' into the mucosal cell which is now 


\begin{tabular}{|c|c|c|c|c|c|c|c|c|c|}
\hline & \multirow{2}{*}{ Volume $(\mathrm{ml})$} & \multicolumn{3}{|c|}{ Concentration $(m M / l)$} & \multicolumn{4}{|c|}{ Solute Load (mM/24 hr) } & \multirow{2}{*}{$\stackrel{\text { DO }}{\stackrel{2}{\vec{T}}}$} \\
\hline & & $N a$ & $\boldsymbol{K}$ & $\mathrm{Cl}$ & $\mathrm{Na}$ & $\boldsymbol{K}$ & $\mathrm{Cl}$ & $\mathrm{Ca}$ & \\
\hline $\begin{array}{l}\text { Saliva } \\
\text { Gastric juice } \\
\text { Bile } \\
\text { Pancreatic juice }\end{array}$ & $\begin{array}{r}1,500 \\
3,000 \\
500 \\
2,000\end{array}$ & $\begin{array}{r}30 \\
50 \\
160 \\
160\end{array}$ & $\begin{array}{r}20 \\
10 \\
5 \\
5\end{array}$ & $\begin{array}{r}35 \\
150 \\
50 \\
30\end{array}$ & $\begin{array}{r}45 \\
150 \\
80 \\
320\end{array}$ & $\begin{array}{r}30 \\
30 \\
3 \\
10\end{array}$ & $\begin{array}{r}52 \\
450 \\
25 \\
60\end{array}$ & 15 & 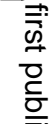 \\
\hline $\begin{array}{l}\text { Internal load } \\
\text { Dietary intake } \\
\text { Total load } \\
\text { Dietary intake as percentage of daily load }\end{array}$ & $\begin{array}{r}7,000 \\
1,500 \\
8,500 \\
18\end{array}$ & & & & $\begin{array}{r}595 \\
170 \\
765 \\
22\end{array}$ & $\begin{array}{r}73 \\
65 \\
138 \\
47\end{array}$ & $\begin{array}{r}587 \\
110 \\
697 \\
16\end{array}$ & $\begin{array}{l}15 \\
22 \\
37 \\
59\end{array}$ & 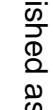 \\
\hline
\end{tabular}

Table I Estimates of quantities of water and solutes entering human intestine daily from gastrointestinal secretions and $\overrightarrow{\mathrm{D}}$ diet (from Carter, Coxon, Parsons, and Thompson, 1959)

thought to supply the power required to pump amino acids and hexoses across the membranes of the brush border into the absorbing cells. In addition the phenomena of water absorption are evidently secondary, although tightly coupled to solute transport. The processes concerned with the membrane transport of sodium therefore seem to be fundamental to intestinal absorptive activity.

When hypotonic solutions are introduced into the lumen it seems to be a feature of the duodenum and jejunum that sodium chloride moves from the blood until the intestinal contents become isotonic. At this point net absorption of the isotonic solution occurs. In the lower parts of the small intestine, on the other hand, a net absorption of sodium chloride occurs from hypotonic solutions. The differences in activity are examples of the different absorptive characteristics of different regions of the intestine (Shay, Gershon-Cohen, Fels, and Munro, 1939; Borgström, Dahlqvist, Lundh, and Sjövall, 1957; McHardy and Parsons, 1957; Code, Bass, McClary, Newnum, and Orris, 1960; Hindle and Code, 1962; Code, 1965; Parsons, 1967). In the jejunum, ileum, and colon there is evidence that the movements of sodium and of chloride are independent of each other to a certain extent and are not necessarily tightly coupled.

\section{SALT ABSORPTION-SODIUM}

There is now clear evidence that the translocation of sodium ions from the intestinal lumen of the mammalian intestine across the epithelial layer is an 'active' process. In other words, sodium movement can proceed against an electrochemical potential gradient existing across the whole wall and is dependent upon metabolic processes occurring within the absorbing cells.

The evidence that the intestinal absorption of sodium can proceed independently of electrical and concentration gradients is given by Curran and Solomon (1957), who undertook studies on the movement of sodium and chloride ions to and fro between the blood and the lumen of the ileum os living rats. They found rates of movement of sodiumis which could not be explained simply in terms of the is electrochemical potential gradient for sodium whichexisted across the epithelial layer.

With identical Ringer solutions bathing both sideso of isolated segments of rat intestine, there is a net? inward transport of sodium ions. This transporte occurs against an electrochemical gradient, for, कै particularly if a substance such as an appropriateo monosaccharide or amino acid is present in the lumen, a potential difference exists across the wholeco wall, the fluid bathing the serosal surface being sorde$10 \mathrm{mV}$ positive to that in the lumen (eg, Bailliento and Schoffeniels, 1961; Clarkson, Cross, and Toote, 1961; Barry, Dikstein, Matthews, Smyth, and Wright, 1964; Curran, 1965; Smith, 1966).

The electrochemical potential gradient across the intestinal wall can be reduced to zero by exposing $\stackrel{\varrho}{\rightarrow}$ the two faces of the tissues to identical bathing solu-o tions, and then clamping the transcellular potential difference to zero volts. Any single ionic species which is subject to independent active transport will then move more rapidly in one direction across the? tissue than in the other, and will contribute to thecurrent which has to be passed through the voltage 3 . clamp circuit in order to maintain zero potential ${ }^{\circ}$ difference across the epithelium. This technique has been applied by Ussing and his associates to the 0 guinea pig caecal mucous membrane where it was found that the net sodium influx was somewhat greater than the short-circuit current. Cooperstein and Hogben (1959) have found that from the $O$ isolated large intestine of the frog the short-circuit $N$ current could almost, but not entirely, be attributed N to sodium transport. Measurements of short-circuit $\sigma$ current have been made in rabbit and rat intestine in vitro by various workers (eg, Schultz and Zalusky, 1964; Barry, Smyth, and Wright, 1965; Schultz and $\stackrel{\oplus}{\rightarrow}$ Curran, 1968). Since in all these experiments there occurs an appreciable net transfer of sodium from the mucosal into the serosal solutions bathing the 
intestine, the sodium transport cannot be explained simply in terms of passive movements down electrochemical gradients existing across the tissue. In the rat and rabbit ileum and in rat colon the sodium transport depends upon aerobic metabolism (Parsons, 1967).

\section{Biochemistry of sodium transport}

The biochemical basis of the sodium pumping mechanism upon which the transcellular transport depends appears to be the membrane bound 'ATPase' which is widely distributed in membranes of many animal cells (Skou, 1965; Glynn, 1968). In this membrane bound system ATP produced by metabolism is hydrolysed by a dephosphorylating system, an integral part of the membrane and intimately concerned with the ionic propulsion mechanism, the chemical potential energy of the nucleotide being employed to translate the sodium ions across the membrane. The hydrolysis of the ATP by the membrane bound systems requires the presence of $\mathrm{Na}^{+}, \mathrm{K}^{+}$, and $\mathrm{Mg}^{++}$ions and is powerfully inhibited by certain cardiac glycosides, for example, ouabain. The transport of $\mathrm{Na}$ across many cell membranes requires the presence of $\mathrm{K}^{+}$in the external medium and is strongly inhibited by ouabain.

The molecular basis of sodium pumping is obscure and many different models have been proposed. One very plausible model based on evidence obtained from erythrocyte membranes is as follows. A channel in an 'empty state' through which the transport occurs accepts at its inner face $\mathrm{Na}$ and Mg ATP. The channel is thereby converted into the ' $\mathrm{Na}$ state' in which $\mathrm{Na}$ is within the channel, some component of which is now phosphorylated. This stage could be associated with the outward transport of the $\mathrm{Na}$ ions through the membrane. In the next stage the sodium, now at the outside end of the channel, is replaced by potassium from the external medium, to form a 'potassium state' of the channel. This state is associated with the inward transport of $\mathrm{K}$ ions and the simultaneous hydrolysis of a phosphorylated channel-complex.

The reactions may be summarized as follows:-

$$
\begin{aligned}
& \mathrm{Mg}++ \\
& \mathrm{ATP}+\mathrm{Na}_{\text {internal }}+\text { empty channel } \rightleftharpoons \\
& \text { Na-channel } \sim \mathbf{P}_{\mathbf{1}}+\text { ADP } \\
& \ldots(1) \\
& \mathrm{K}_{\text {external }}+\mathrm{Na} \text {-channel } \sim \mathbf{P}_{\mathbf{i}} \rightleftharpoons \\
& \text { K-channel } \sim \mathbf{P}_{\mathbf{1}}+\mathbf{N a} \mathbf{N}_{\text {external }} \\
& \text { K-channel } \sim \mathbf{P}_{\mathbf{i}} \rightleftharpoons \\
& \text { empty channel }+\mathbf{K}_{\text {internal }}+\mathbf{P}_{\mathbf{i}}
\end{aligned}
$$

The maintenance of $\mathrm{Na}$ pumping therefore requires a continual supply of ATP. Exposure to metabolically unfavourable conditions, eg, tem- peratures below $30^{\circ}$, anoxia, etc, therefore rapidly inhibits salt transport across the intestinal mucosa.

\section{SALT ABSORPTION-CHLORIDE}

Sodium ion movements across membranes are accompanied by movements of other ions. Either the $\mathrm{Na}$ exchanges for $\mathrm{H}^{-}$ions or $\mathrm{K}$ ions for example, or it is accompanied by an anion, for example $\mathrm{Cl}^{-}$ or $\mathrm{HCO}_{3}{ }^{-}$.

\section{Active transport of chloride in tissues}

The active transport of chloride ions, ie, the movement of chloride ions in the absence of either any external driving force, such as an electrochemical gradient, or the movement of chloride ions up an adverse electrochemical gradient, has now been demonstrated in the following tissues: in the frog cornea (Zadunaisky, 1966), the direction being from the aqueous humour towards the tears; across fish gills (Romeu and Maetz, 1964); across the gastric mucosa from the blood to the lumen (Hogben, 1955); across the rumen epithelium (Stevens, 1964); across frog skin (Zadunaisky, Candia, and Chiarandini, 1963); and across the skin of larvae of salamanders (Dietz, Kirschner, and Porter, 1967). There is also evidence that the chloride movement across the urinary bladder of the turtle and also across fish gallbladder is active (Brodsky and Schilb, 1966; Diamond, 1968). It is also known that the chloride ions inside the giant nerve fibres of the squid are not in electrochemical equilibrium with the environment and that the ion appears to be subjected to an inward, active transport (Keynes, 1962 and 1963). The biochemical events associated with the membrane pumping of chloride are not known.

\section{Active transport of chloride by intestinal mucosa}

It has been known since the middle of the last century that isosmotic solutions of sodium chloride are absorbed from the lumen of the jejunum and that hypoosmotic solutions are absorbed from the ileum. This basic observation has been repeated many times in experiments conducted in vitro as well as in living animals. However, it is important to realize that the demonstration of net transport of chloride ions in the absence of any concentration difference or even against a concentration gradient is not a formal demonstration of active chloride transport. Whether or not the transport is active will also depend upon the magnitude and direction of any voltage existing across the epithelial layer.

When identical solutions containing sodium chloride are placed on both sides of intestine surviving in vitro, a small voltage appears across the mucosal layers, the serosal surface being positive to the mucosal. Under these conditions a net inward 
movement of chloride into the serosal fluid cannot be taken as a formal demonstration of active chloride transport. It has often been shown, for example, in dog intestine and rat intestine (Ingraham and Visscher, 1936; McHardy and Parsons, 1957) that hypotonic solutions of sodium chloride are rapidly absorbed from ileal segments. Visscher also showed that chloride movements across dog intestine were not explicable in terms of simple diffusion (eg, Visscher, Varco, Carr, Dean, and Erickson, 1944b). However, in none of these experiments were voltage measurements made, so the experimental findings do not constitute a formal demonstration of active chloride transport. More recently, Curran and Solomon (1957) have measured chloride movements, net and unidirectional, and the potential differences across rat ileum in vivo while salt absorption was proceeding. Similar measurements have been made on dog ileum in vivo by Kinney and Code (1964). These observations have shown unequivocally that the chloride as well as sodium is transported against an electrochemical potential gradient and therefore actively from the lumen into the plasma by this tissue. It will be observed that, with $75 \mathrm{mM} \mathrm{NaCl}$ in the lumen, for the net inward transport of chloride into tissue fluid containing $150 \mathrm{mM} \mathrm{NaCl}$ to be passive, then the potential difference across the intestine must be at least $18 \mathrm{mV}$, the serosal side being positive.

The absorption of chloride ions from duodenal or jejunal segments, but particularly from duodenal segments, exhibits different characteristics. The introduction of hypotonic solutions into the lumen results in the net entry of both sodium and chloride into that compartment at the same time that water absorption proceeds. When isotonicity has been achieved the isotonic absorption of the salt solution begins, a state of affairs which is in contrast to that obtaining in the ileum or colon.

It is not to be imagined that salt absorption is a one-way process. Labelled sodium or chloride placed in the intestinal lumen rapidly appears in the blood. Labelled sodium or chloride placed in the blood rapidly appears in the intestinal lumen. Water behaves in a similar fashion. In fact, net absorption of salt is the algebraic resultant of two unidirectional fluxes, lumen to blood and blood to lumen. Compared with the net rates, the magnitudes of the unidirectional rates are high (Tables II and III). These findings imply that sodium may move rapidly across the cell membranes and that if the bidirectional fluxes are independent of each other, an inhibition of, say, the influx (lumen $\rightarrow$ blood) could turn 'absorption from the lumen' into 'secretion into the lumen'. An independence of fluxes might follow if, from the point of view of sodium pumping, the cells were more symmetrical than indicated in Fig. 2, so that both faces of the cells (lumen and blood) were furnished with outwardly directed sodium pumps, $\stackrel{\vec{\partial}}{\mathrm{c}}$ that in the basal pole being more active. The fact that brush border membranes contain ATPases is $\underset{\vec{P}}{\vec{P}}$ perhaps consistent with this possibility.

\begin{tabular}{llll}
\hline & \multicolumn{4}{l}{ Sodium Flux $(\mu$ Mol/min $)$} \\
\cline { 2 - 4 } & From Lumen & Into Lumen & Net \\
\hline Jejunum & 214 & 184 & 30 \\
Ileum & 263 & 168 & 95 \\
Colon & 104 & 40 & 64 \\
\hline
\end{tabular}

Table II Bidirectional sodium movements between 용 contents of intestinal lumen of dog intestine at different is locations and blood (from Visscher et al, 1944b)

\begin{tabular}{lcc}
\hline Flux & & Net \\
\hline From Lumen & $28 \pm 12(8)$ & $48 \pm 9$ \\
\hline $\begin{array}{l}\text { Into Lumen }(\mu \text { Mol /min }) \\
\begin{array}{l}\text { Water }(\mu \text { l/min }) \\
1,110 \pm 70(14)\end{array}\end{array}$ & $950 \pm 80(14)$ & $170 \pm 60$
\end{tabular}

Table III Bidirectional movements of water and chloride between contents of lumen in dog ileum and blood (from Visscher et al, 1944a)

ACID-BASE CHANGES DURING SALT ABSORPTION

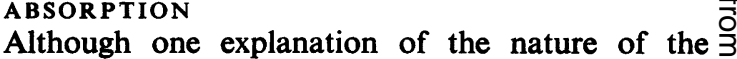
process of chloride absorption would be that the $\bar{P}$ chloride ions accompany the sodium which is being ? absorbed either passively or actively, by the functioning of an electroneutral $\mathrm{NaCl}$ pump, the case does not appear to be as simple as this. In fact, chloride ions appear to be absorbed at rates which differ from that of sodium. Furthermore, the relative rates of chloride and sodium absorption differ in the various regions of the intestinal tract. These differences in chloride absorption at differing parts of the intestine may be related to the fact that during absorption bicarbonate-saline solutions in the upper $N$ small intestine become adjusted to $p \mathrm{H}$ values which are more acid (about $p \mathrm{H} \mathrm{6.5)}$ than in the ileum or colon (about $p \mathbf{H} 7 \cdot 5$ ). Bicarbonate ions rapidly disappear from rat jejunal contents but are secreted $\mathscr{O}$ into the contents of the ileum during the absorption 0 of bicarbonate saline solutions (Parsons, 1956; $\mathbb{\varnothing}$ Swallow and Code, 1967). Figure 3 shows the changes in concentration of total $\mathrm{CO}_{2}$ which occur during absorption from bicarbonate saline solutions 
in rat intestine, and the net movements of salt and of $\mathrm{CO}_{2}$ and water are shown in Table IV.

\begin{tabular}{|c|c|c|c|c|}
\hline Site & $\begin{array}{l}\text { No. of } \\
\text { Animals }\end{array}$ & $\mathrm{Na}$ & $\mathrm{Cl}$ & Total $\mathrm{CO}_{2}$ \\
\hline $\begin{array}{l}\text { Jejunum } \\
\text { Ileum } \\
\text { Colon }\end{array}$ & $\begin{array}{l}6 \\
6 \\
6\end{array}$ & $\begin{array}{r}10.17 \pm 1.05 \\
5.56 \pm 0.62 \\
6.95 \pm 0.38\end{array}$ & $\begin{array}{l}5.97 \pm 0.75 \\
6.52 \pm 0.28 \\
7.26 \pm 0.44\end{array}$ & $\begin{array}{r}3.80 \pm 0.29 \\
-1.11 \pm 0.26^{2} \\
-0.64 \pm 0.15\end{array}$ \\
\hline
\end{tabular}

Table IV Absorption of $\mathrm{NaCl}$ and $\mathrm{CO}_{2}$ from $\mathrm{NaCl}$ $\mathrm{NaHCO}_{3}$ solutions in lumen of rat intestine ${ }^{1}$ (data of Parsons, 1956)

'Values, $\mu \mathrm{M} / \mathrm{mg}$ dry weight $/ 4 \mathrm{hr}$ are net movements.

${ }^{2}$ Negative values signify entry into luminal contents.

In the hamster, bicarbonate secretion into the lumen occurs along the whole small intestine (Wilson and Kazyak, 1957). An entry of bicarbonate occurs during the absorption of saline solutions instilled into the colon of the dog and of man. The secretion of bicarbonate ions into the lumen of the rat ileum appears to depend upon the presence of chloride ions in the intestinal lumen (Hubel, 1967).

One way of describing these findings is to say that the anions which accompany the sodium during the absorption differ at different sites in the intestine. From isotonic solutions in the intestinal lumen and which contain $\mathrm{NaCl}-\mathrm{NaHCO}_{3}$, the absorbed sodium is accompanied in the jejunum by both $\mathrm{Cl}$ ions and $\mathrm{HCO}_{3}$ ions. In the ileum and colon, on the other hand, the chloride absorption is at least as great as that of the sodium, and some of the chloride behaves as if the absorption occurs in exchange for bicarbonate ions.

A possible model to account for these phenomena would be as follows. Part of the sodium ions is absorbed accompanied by chloride, perhaps through the operation of an electroneutral pump. Especially in the jejunum, other sodium ions are absorbed in exchange for $\mathrm{H}$ ions. Although some $\mathrm{Cl}$ ions may be absorbed accompanied by $\mathrm{Na}$, some $\mathrm{Cl}$ ions are absorbed, especially in the ileum, in exchange for $\mathrm{HCO}_{3}$ ions. With $\mathrm{HCO}_{3}$ ions present in the luminal contents, the addition of $\mathrm{H}$ ions to the lumen during $\mathrm{Na}$ absorption will lead to the conversion of $\mathrm{HCO}_{3}$ ions to $\mathrm{CO}_{2}$. The idea that in the jejunum bicarbonate ions are 'absorbed' as $\mathrm{CO}_{2}$ is supported by the fact that the $\mathrm{pCO}_{2}$ of the contents of the lumen of
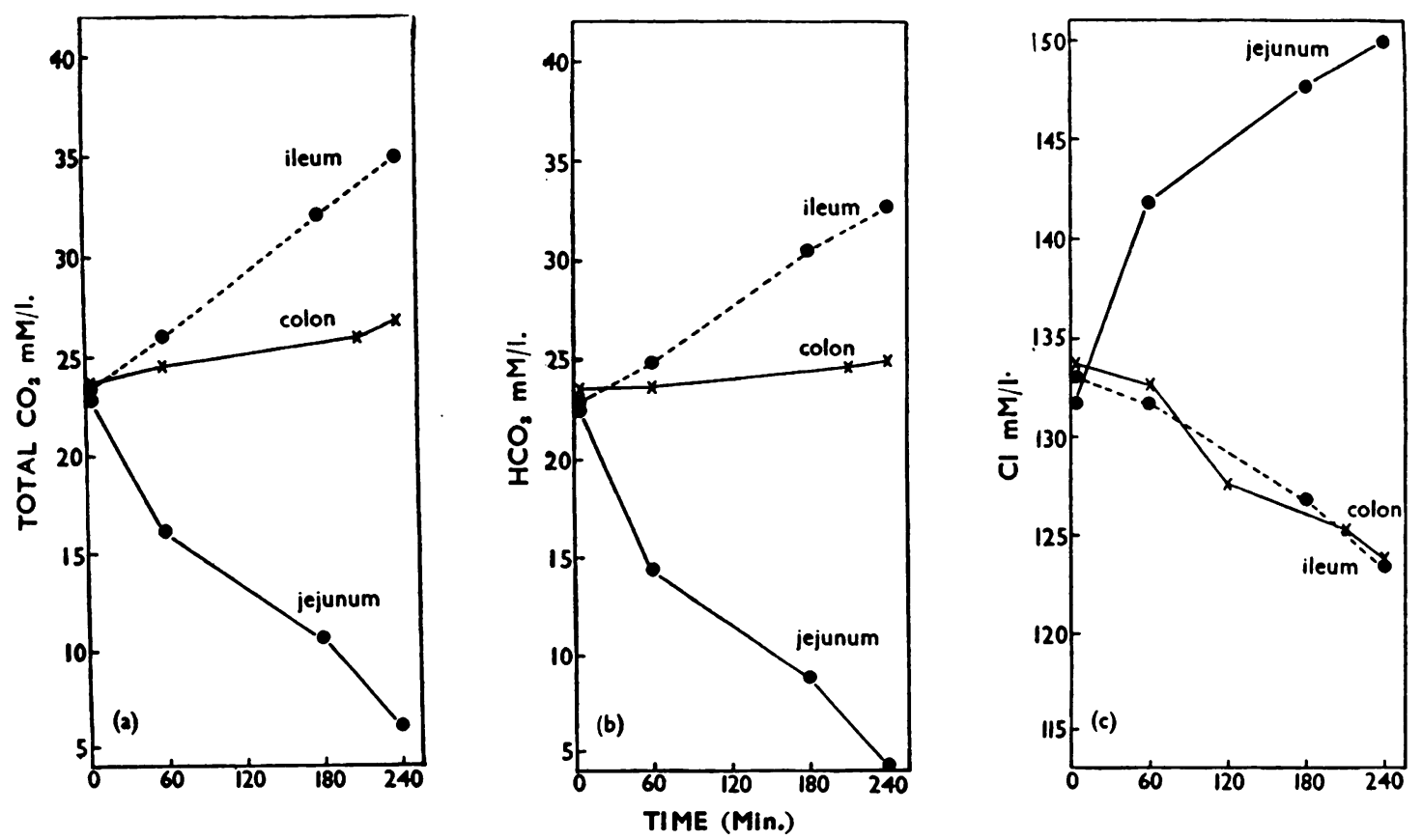

Fig. 3 Changes in concentration in luminal contents of rat intestine during absorption. Solutions containing $160 \mathrm{mM} / \mathrm{l} \mathrm{Na}, 135 \mathrm{mM} / \mathrm{l} \mathrm{Cl}$, and $25 \mathrm{mM} / \mathrm{l} \mathrm{HCO}_{3}^{-}$were equilibrated with $5 \%(\mathrm{v} / \mathrm{v}) \mathrm{CO}_{2}$ and recirculated under closed conditions. Total $\mathrm{CO}_{2}$ (left), $\mathrm{HCO}_{3}^{-}$(middle), and $\mathrm{Cl}^{-}$(right). (From Parsons, 1956.) 
the jejunum is always higher than that of the contents of the ileum (Parsons, 1956; Swallow and Code, 1967).

These changes in acid-base pattern of the intestinal contents must be reflected in the composition of the venous blood draining the intestine. Thus for every millimole of $\mathrm{HCO}_{3}$ ions secreted, net, into the contents of the lower intestine, one millimole of $\mathrm{H}$ ions must appear in the venous blood draining that region.

Acid-base changes occurring during absorption have other important implications additional to those relating to the absorption of $\mathrm{NaCl}$. The existence of different equilibrium values for $p \mathrm{H}$ and $\mathrm{HCO}_{3}$ concentration at differing locations in the intestinal tract of various species including man has implications with respect to the absorption of weak electrolytes including drugs. Further, the value of the local $\mathrm{H}$-ion activity at different sites along the intestine is of profound significance in determining the activity of the various digestive enzymes which are responsible for the cleavage of the polymeric foodstuffs present in the diet.

\section{COLON}

The colon in vitro behaves towards simple saline solutions in much the same way as does the small intestine, particularly the ileum. However, under conditions in vivo the colonic contents differ from those of the small intestine in that they contain appreciable quantities of ammonium and fatty acids produced by fermentation. It appears to be likely that the movements of these substances may interact with those of sodium and chloride in an interesting fashion. For example, in rat colon in the presence of ammonium ions $(10 \mathrm{mM})$ there is an absorption of $\mathrm{CO}_{2}$ from bicarbonate solutions (Parsons and Powis, 1971).

\section{Influence of Bicarbonate Ions and $p H$}

There is evidence that bicarbonate ions stimulate sodium and water absorption by the human small intestine invivo (Sladen and Dawson, 1968; Fordtran,
Rector, and Carter, 1968). I now wish to describe experiments which show a significant stimulation by $\mathrm{CO}_{2}$ and bicarbonate ions of the transport of water and electrolytes across rat jejunum in vitro. We do $\overrightarrow{\vec{F}}$ not find an effect on transport across the ileum. (These experiments were undertaken in my laboratory by Dr John Dupré now at Montreal and Dr Gordon Sladen of St Bartholomew's Hospital.)

Male albino rats of local strain (170-250 g) were $\varnothing$ used. Warmed oxygenated Krebs-Ringer solutions क of differing $p \mathrm{H}$, buffered with either phosphate or $\overrightarrow{0}$ bicarbonate, were circulated through $20-40 \mathrm{~cm}$ lengths of intestine in vitro, using a technique similar $\vec{\omega}$ to that described by Parsons and Wingate (1961), except that the segments were immersed in liquid paraffin and the transported fluid collected as the secreted 'sweat'. The bicarbonate concentrations in used were $25 \mathrm{mM}(p \mathrm{H} \mathrm{7.4)}, 5 \mathrm{mM}(p \mathrm{H} \mathrm{6.8)}$ and $\overrightarrow{0}$ $2.5 \mathrm{mM}(p \mathrm{H} 6.4)$. In the phosphate-containing $\varnothing$ solutions the total phosphate concentration was 을 $10 \mathrm{mM}$.

The bicarbonate-containing solutions were gassed with $5 \%(\mathrm{v} / \mathrm{v}) \mathrm{CO}_{2}-95 \%(\mathrm{v} / \mathrm{v}) \mathrm{O}_{2}$, the phosphate solutions with $100 \%(\mathrm{v} / \mathrm{v}) \mathrm{O}_{2}$. All solutions contained glucose $(500 \mathrm{mg} / 100 \mathrm{ml})$. Under these conditions after an initial latent period $(5 \mathrm{~min}$ for jejunum 15-20 min for ileum) fluid begins to appear in the serosal compartment, and continues to be secrete at an approximately constant rate for periods of more than two hours. During this time volumes of fluid were collected at intervals of 15 to $20 \mathrm{~min}$, measured volumetrically and subsequently analysed for glucose (glucose oxidase), $\mathrm{Na}$ (flame photometry), and $\mathrm{Cl}$ (coulometric titration). The length and fat-free dry weight (FFDW) of the segment were measured.

In the jejunum (Table $\mathrm{V}$ ) at $p \mathbf{H ~} 7 \cdot 4$ there is a higher transfer rate of water $(\mathrm{P}<0.001), \mathrm{Na}(\mathrm{P}<0.001)$, and $\mathrm{Cl}(\mathrm{P}<0.01)$ from the bicarbonate than from the phosphate solutions. Over the range 6.4-7.4 increasing $p \mathrm{H}$ markedly stimulates salt and water transport $(\mathrm{P}<0.01$ for $\mathrm{Na}, \mathrm{Cl}$, and water). At $p \mathrm{H} 6.4$ there is no difference between transport rates from bicarbonate and phosphate solutions. This

\begin{tabular}{|c|c|c|c|c|c|}
\hline Fluid in Intestinal Lumen & Initial Luminal $\mathrm{p} H$ & Water $(\mu l)$ & Glucose (mg) & Sodium $(\mu M)$ & Chloride $(\mu M)$ \\
\hline $\mathrm{CO}_{2} /$ bicarbonate medium & $\begin{array}{l}7 \cdot 4 \\
68 \\
6 \cdot 4\end{array}$ & $\begin{array}{l}353 \pm 16(8) \\
178 \pm 9(5) \\
103 \pm 13(5)\end{array}$ & $\begin{array}{l}1.89 \pm 0.08(5) \\
1.65 \pm 0.15(5) \\
0.83 \pm 0.13(4)\end{array}$ & $\begin{array}{l}46 \cdot 3 \pm 1 \cdot 3(5) \\
22 \cdot 6 \pm 2 \cdot 1(5) \\
12 \cdot 7 \pm 1 \cdot 7(4)\end{array}$ & $\begin{array}{l}26.4 \pm 1.8(6) \\
16.0 \pm 1.6(5) \\
10.3 \pm 1.4(4)\end{array}$ \\
\hline Phosphate medium & $\begin{array}{l}7 \cdot 4 \\
6 \cdot 4\end{array}$ & $\begin{array}{r}186 \pm 19(8) \\
84 \pm 14(4)\end{array}$ & $\begin{array}{l}1.66 \pm 0.19(6) \\
0.39 \pm 0.06(4)\end{array}$ & $\begin{array}{l}22 \cdot 3 \pm 1 \cdot 8(6) \\
11 \cdot 5 \pm 2 \cdot 1(4)\end{array}$ & $\begin{array}{r}16.6 \div 2.2(6) \\
9.2 \pm 1.7(4)\end{array}$ \\
\hline
\end{tabular}

Table $\mathrm{V}$ Influence of $\mathrm{CO}_{2}$ and bicarbonate in luminal fluid on the transfer of water and solutes across rat jejunum in vitro ${ }^{1}$

${ }^{1}$ Units are given per minute/g fat-free dry weight. Values are means $\pm S E$ of $m$ sans. The number of observations are given in parentheses. 


\begin{tabular}{lccc}
\hline & Fluid in Intestinal Lumen \\
\cline { 2 - 4 } & CO, Bicarbonate Medium & Phosphate Medium \\
\hline Water $(\mu \mathrm{l})$ & $170 \pm 15(10)$ & $142 \pm 12(9)$ \\
Glucose $(\mathrm{mg})$ & $0.57 \pm 0.09(10)$ & $1.0 \pm 0.25(9)$ \\
Sodium $(\mu \mathrm{M})$ & $24.8 \pm 2.4(10)$ & $19.8 \pm 1.3(9)$ \\
Chloride $(\mu \mathrm{M})$ & $17.4 \pm 2.4(10)$ & $13.6 \pm 1.0(9)$ \\
\hline
\end{tabular}

Table VI Influence of $\mathrm{CO}_{2}$ and bicarbonate $(25 \mathrm{mM})$ in luminal fluid at $\mathrm{pH} 7.4$ on transfer of water and solutes across rat ileum in vitro ${ }^{1}$

${ }^{1}$ Units are given per minute/g fat-free dry weight. Values are means $\pm \mathrm{SE}$ of means. Number of observations given in parentheses.

finding may be related to the low bicarbonate concentration of $2.5 \mathrm{mM}$ at $p \mathrm{H} 6.4$ compared with

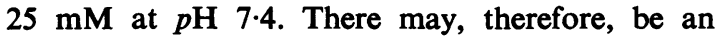
additive effect of both $p \mathrm{H}$ and $\mathrm{HCO}_{3}{ }^{-}$concentration. A significant stimulating effect of $p H$ is found on the rates of glucose transfer $(P<0.01)$. However, in the absence of data on the rate of glucose metabolism, the rates of transfer cannot be related to the rates of glucose absorption from the lumen. In the ileum at $p \mathrm{H} 7.4$ (Table VI) there is no difference between the transport rates from bicarbonate and phosphate solutions ( $P>0.1$ in each case).

It is concluded that the presence of $\mathrm{CO}_{2}$ and bicarbonate ions in the lumen at $p \mathrm{H} 7.4$ stimulates the jejunal, but not ileal, transport of water, $\mathrm{Na}$, and $\mathrm{Cl}$, and that the effect is $p \mathrm{H}$-dependent, being absent at $p \mathrm{H} 6.4$.

It was mentioned earlier that bicarbonate is 'absorbed' by rat jejunum, but is secreted by the ileum. If absorbed with an accompanying cation, presumably $\mathrm{Na}$, then the net transport of $\mathrm{NaHCO}_{3}$ would be associated with increased fluid transport (McHardy and Parsons, 1957). Movements of $\mathrm{H}^{+}$ may be of primary importance in producing bicarbonate 'absorption' (Parsons, 1956; Fordtran and Dietschy, 1966), so that the absorption of $\mathrm{Na}^{+}$ in exchange for $\mathrm{H}^{+}$might account for the effect of bicarbonate in stimulating $\mathrm{Na}$ absorption in the jejunum (Parsons, 1956; Fordtran et al, 1968). But neither of these mechanisms accounts for the stimulated transport of $\mathrm{Cl}$. It is therefore possible that bicarbonate might promote $\mathrm{NaCl}$ transport indirectly. The entry of $\mathrm{Na}$ (and perhaps $\mathrm{Cl}$ ) might be stimulated, as was suggested by Funder, Ussing, and Wieth (1967) to account for their findings concerning the effect of $\mathrm{CO}_{2}$ and bicarbonate on $\mathrm{NaCl}$ transport by isolated frog skin. Alternatively, the exit mechanism of $\mathrm{Na}$ transport may be stimulated. It is known that bicarbonate ions and a high $p \mathrm{H}$ in the lumen promote mucosal utilization of glucose, at least in rat jejunum (Wilson, 1956; Jackson, Levin, and Thompson, 1968). Furthermore, the rate of sodium and water transport in rat jejunum is dependent on a supply of glucose (Gilman and Koelle, 1960). However, there is no evidence to suggest that the supply or metabolism of glucose is in any way rate-limiting to net $\mathrm{Na}$ transport.

It is of interest that although the intestinal absorption of salt is inhibited in the presence of the carbonic anhydrase inhibitor acetazolamide (Parsons, 1956), there appears to be little of this enzyme within the mucosal cells (Carter and Parsons, 1968).

\section{Conclusions}

It appears that many of the absorptive activities of the gastrointestinal tract depend upon the functioning of membrane transport systems located in the limiting membranes which bound the cells of the mucosal epithelium. In particular the membrane transport processes for salt appear to be fundamental to intestinal absorption in that the transport of $\mathrm{Na}$ ions appears to be closely coupled to the transport of other substances, notably to that of the amino acids and of the sugars. Salt absorption is also, of course, coupled to the transepithelial transport of water. The membrane processes which underlie sodium transfer are believed to be related to the 'ATPase' systems which constitute an integral part of the biochemical architecture of cell membranes. The maintenance of salt transport therefore requires a continuing metabolism on the part of the cells in order to sustain this supply of ATP. Salt absorption is therefore inhibited if the intestine is exposed to a metabolically unfavourable environment, eg, if it is cooled.

The net absorption of salt, which is a fundamental activity of the gastrointestinal tract, is essentially a two-way process, the net absorption observed being associated with the occurrence of massive bidirectional fluxes across the cells. To some extent the rates of absorption of $\mathrm{Na}$ and of $\mathrm{Cl}$ are independent and occur at differing rates, electrical neutrality being maintained by appropriate movements of bicarbonate. These movements are associated with the different acid-base changes which are characteristic of salt absorption at different positions along the length of the intestinal tract. There is also evidence that $\mathrm{CO}_{2}$ or bicarbonate may play a key role in salt transport in the jejunum, but whether the effects are mediated upon $\mathrm{Na}$ or upon $\mathrm{Cl}$ absorbing processes remains to be discovered.

It is also important to appreciate that much remains to be discovered about salt transfer across the epithelial layers of many tissues, including the intestine. For example, how does salt move through the cell from one side to the other? Does simple diffusion play a significant role or is some intracellular transport system involved? Finally, it is 
important to appreciate that the functioning of the epithelial sheet which forms the intestinal mucosa depends not only upon the biochemical and physiological activities of the individual cells, but also upon the functional and architectural relationships which exist between the cells. The physiological properties of the epithelial sheet transcend those of the individual cells.

\section{References}

Baillien, M., and Schoffeniels, E. (1961). Origine des potentiels bioelectriques de l'epithelium intestinal de la tortue grecque. Biochim. biophys. Acta (Amst.), 53, 537-548.

Barry, R. J. C., Dikstein, S., Matthews, J., Smyth, D. H., and Wright, E. M. (1964). Electrical potentials associated with intestinal sugar transfer. J. Physiol. (Lond.), 171, 316-338.

Barry, R. J. C., Smyth, D. H., and Wright, E. M. (1965). Short-circuit current and solute transfer by rat jejunum. J. Physiol. (Lond.), $181,410-431$.

Borgström, B., Dahlqvist, A., Lundh, G., and Sjövall, J. (1957). Studies of intestinal digestion and absorption in the human. J. clin. Invest., 36, 1521-1536.

Brodsky, W. A., and Schilb, T. P. (1966). Ionic mechanisms for sodium and chloride transport across turtle bladders. Amer. J. Physiol., 210, 987-996.

Carter, C. W., Coxon, R. V., Parsons, D. S., and Thompson, R. H. S. (1959). Biochemistry in Relation to Medicine, ch. 11. Longmans, New York.

Carter, M. J., and Parsons, D. S. (1968). Carbonic anhydrase activity in mucosa of small intestine and colon. Nature (Lond.), 219, 176-177.

Clarkson, T. W., Cross, A. C., and Toole, S. R. (1961). Electrical potentials across isolated small intestine of the rat. Amer. $J$. Physiol., 200, 1233-1235.

Code, C. F. (1965). Sorption of water and electrolyte in healthy persons: A brief review. In Proceedings of the Cholera Research Symposium, edited by O. A. Bushnell and C. S. Brookhyser, pp. 87-98. US Department of Health Education and Welfare, Washington DC.

Code, C. F., Bass, P., McClary, G. B., Jr., Newnum, R. L., and Orris, A. L. (1960). Absorption of water, sodium and potassium in small intestine in dogs. Amer. J. Physiol., 199, 281-288.

Cooperstein, I. L., and Hogben, C. A. M. (1959). Ionic transfer across the isolated frog large intestine. J. gen. Physiol., 42, 462-473.

Curran, P F. (1965). Ion transport in intestine and its coupling to other transport processes. Fed. Proc., 24, 993-999.

Curran, P. F., and Solomon, A. K. (1957). Ion and water fluxes in the ileum of rats. J. gen. Physiol., 41, 143-168.

Diamond, J. M. (1968). In Handbook of Physiology, section 6, vol. 5, ch. 115, pp. 2451-2482. American Physiological Society, Washington DC.

Dietz, T. H., Kirschner, L. B., and Porter, D. (1967). The roles of sodium transport and anion permeability in generating transepithelial potential differences in larval salamanders. J. exp. Biol., 46, 85-96.

Dowben, R. M. (1969). General Physiology. Harper and Row, New York and London.

Fordtran, J. S., and Dietschy, J. M. (1966). Water and electrolyte movement in the intestine. Gastroenterology, 50, 263-285.

Fordtran, J. S., Rector, F. C., and Carter, N. W. (1968). The mechanisms of sodium absorption in the human small intestine. J. clin. Invest., 47, 884-900.

Funder, J., Ussing, H. H., and Wieth, J. O. (1967). The effects of $\mathrm{CO}_{2}$ and hydrogen ions on active $\mathrm{Na}$ transport in the isolated frog skin. Acta Physiol. scand., 71, 65-76.

Gilman, A., and Koelle, E. S. (1960). Substrate requirements for ion transport by rat intestine studied in vitro. Amer. J. Physiol. 199, 1025-1029.

Glynn, I. M. (1968). Membrane adenosine triphosphate and cation transport. Brit. med. Bull., 24, 165-169.

Hindle, W., and Code, C. F. (1962). Some differences between duodenal and ileal sorption. Amer. J. Physiol., 203, 215-220.

Hodgkin, A. L. (1964). The Sherrington Lectures. VII: The Conduction of the Nervous Impulse Liverpool University Press.
Hogben, C. A. M. (1955). Active transport of chloride by isolated frog gastric epithelium. Origin of the gastric mucosal potential. Amer. J. Physiol., 180, 641-649.

Hubel, K. A. (1967). Bicarbonate secretion in rat ileum and its 0 dependence on intraluminal chloride. Amer. J. Physiol., 213, 1409-1413.

Ingraham, R. C., and Visscher, M. B. (1936). The influence of various $\stackrel{\vec{\sigma}}{\overrightarrow{+}}$ poisons on the movement of chloride against concentration gradients from intestine to plasma. Amer. J. Physiol., 114, 681-687.

Jackson, M. J., Levin, R. J., and Thompson, E. (1968). The influence $\overline{\overline{\mathcal{S}}}$ of $p \mathrm{H}$ on intestinal metabolism and transport in vivo. J. Physiol. $\vec{\nabla}$ (Lond.). 197, 16P-17P.

Katz, B. (1966). Nerve, Muscle and Synapse. McGraw-Hill, New York.

Keynes, R. D. (1962). Active transport of chloride in the squid giant $\mathscr{C}$ axon. J. Physiol. (Lond.), 163, 19P-20P.

Keynes, R. D. (1963). Chloride in the squid giant axon. J. Physiol. (Lond.), 169, 690-705.

Kinney, V. R., and Code, C. F. (1964). Canine ileal chloride absorp- $\vec{\omega}$ tion: effect of carbonic anhydrase inhibitor on transport. S Amer. J. Physiol., 207, 998-1004.

McHardy, G. J. R., and Parsons, D. S. (1957). The absorption of water and salt from the small intestine of the rat. Quart. J. exp. Physiol., 42, 33-48.

Parsons, D. S. (1956). The absorption of bicarbonate-saline solutions or by the small intestine and colon of the white rat. Quart.J. exp. Physiol., 41, 410-420.

Parsons, D. S. (1967). Salt and water absorption by the intestinal trast. Brit. med. Bull., 23, 252-257.

Parsons, D. S., and Powis, G. (1971).J. Physiol. (Lond.) (In the press.

Parsons, D. S., and Wingate, D. L. (1961). The effect of osmotic gradients on fluid transfer across rat intestine in vitro. Biochim. biophys. Acta (Amst.), 46, 170-183.

Romeu. F. G., and Maetz, J. (1964). The mechanisms of sodium and chloride uptake by the gills of a fresh-water fish Carassius auratus. I. Evidence for an independent uptake of sodium and chloride ions. J. gen. Physiol., 47, 1195-1207.

Schultz, S. G., and Curran, P. F. (1968). In Handbook of Physiology section 6, vol. 3, ch. 66, pp. 1245-1276. American Physiologigl . Society, Washington DC.

Schultz, S. G., and Curran, P. F. (1970). Coupled transport of sodi and organic solutes. Physiol. Rev., 50, 637-718.

Schultz, S. G., and Zalusky, R. (1964). Ion transport in isolated rab光 ileum. I. Short-circuit current and $\mathrm{Na}$ fluxes. J. gen. Physiol. $47,567-584$.

Schwann, T. (1847). Microscopical Researches into the Accordance in the Structure and Growth of Animals and Plants, translated by H. Smith (1847.) Sydenham Society, London.

Shay, H., Gershon-Cohen, J., Fels, S. S., and Munro, F. L. (1939). The absorption and dilution of glucose solutions in the human stomach and duodenum. Amer. J. dig. Dis., 6, 535-544.

Skou, J. C. (1965). Enzymatic basis for active transport of $\mathrm{Na}^{+}$and $\mathrm{K}^{+}$across cell membrane. Physiol. Rev., 45, 596-617.

Sladen, G. E., and Dawson, A. M. (1968). Effect of bicarbonate on sodium absorption by the human jejunum. Nature (Lond.), 218, 267-268.

Smith, M. W. (1966). Sodium-glucose interactions in the goldfish 3 intestine. J. Physiol. (Lond.), 182, 559-573.

Stevens, C. E. (1964). Transport of sodium and chloride by the isolated rumen epithelium. Amer. J. Physiol., 206, 1099-1105.

Swallow, J. H., and Code, C. F. (1967). Intestinal transmucosal fluxes of bicarbonate. Amer. J. Physiol., 212, 717-723.

Visscher, M. B., Fetcher, E. S., Carr, C. W., Gregor, H. P., Bushey, M. S., and Barker, D. E. (1944a). Isotopic tracer studies on the movement of water and ions between intestinal lumen and blood. Amer. J. Physiol., 142, 550-575.

Visscher, M. B., Varco, R. H., Carr, C. W., Dean, R. B., and Erickson, O D. (1944b). Sodium ion movement between the intestinal lumen and the blood. Amer. J. Physiol., 141, 488-505.

Wilson, T. H. (1956). The role of lactic acid production in glucose $N$ absorption from the intestine. J. biol. Chem. 222, 751-763.

Wilson, T. H., and Kazyak, L. (1957). Acid base changes across the wall in hamster and rat intestine. Biochim. biophys. Acta (Antst.) 24, 124-132.

Zadunaisky, J. A. (1966). Active transport of chloride in frog cornea. Amer. J. Physiol., 211, 506-512.

Zadunaisky, J. A., Candia, O. A., and Chiarandini, D. J. (1963) The origin of the short-circuit current in the isolated skin of the south American frog. Leptodactylus ocellatus. J. gen. Physiol., 47, 393-402. 